\title{
Controlled High-Temperature Sintering of Boron Carbide
}

\author{
Nikolay Stoimenov ${ }^{1, *}$, Bogomil Popov ${ }^{1}$, Veneta Yosifova ${ }^{1}$ \\ ${ }^{1}$ Institute of Information and Communication Technologies, bl. 2, ac. G. Bonchev str.1113 Sofia, Bulgaria
}

\begin{abstract}
The paper discusses the boron carbide properties. Two methods are used to examine and control the sintering process of micro/nano boron carbide. For achieving sintering is used a Tammann furnace. First, it is used an electric furnace with the thermal couple for determining transmission coefficient of $\mathrm{ZnSe}$ infrared window, observed with an infrared thermal camera. Analysis of the temperatures with and without infrared glass are discussed. After setting the transmission coefficient to the camera, the material is sintered to desired temperatures and for the temperature control is used an infrared camera. The result of the temperature control is achieved boron carbide material, obtained in strict temperature environment.
\end{abstract}

\section{Introduction}

The Boron carbide was synthesized more than a century ago in 1883 by Joly. The $\mathrm{B}_{4} \mathrm{C}$ formula was identified in 1934 [1]. Today, the range of homogeneity of the compound ranged from $\mathrm{B}_{4.3} \mathrm{C}$ to $\mathrm{B}_{10.4} \mathrm{C}$. The composition of commercial boron carbide is typically close to the stoichiometry of boron:carbon of $4: 1$. Boron carbide is an extremely hard material with a lower hardness of only diamond and cubic boron nitride. In addition, it has a high melting point, approximately at $2490{ }^{\circ} \mathrm{C}(13,3 \mathrm{~mol} \%$ C) and forms a eutectic with carbon at $2220-2260{ }^{\circ} \mathrm{C}$. It has a high mechanical strength combined with low density and high cross-section neutron grip and it is a semiconductor [2]. It is difficult to sinter to full density, usually boron carbide is produced with an addition of sintering aids such as fine carbon or silicon carbide [3].

Boron carbide is characterized by: Exceptional hardness; Low thermal conductivity; High elastic module; High compressive strength; Good nuclear properties; Low density. Boron carbide have a profile of properties that are appreciated in a wide range of applications such as mining industry, aerospace, military industry, abrasives requiring extreme hardness for use in polishing and bonding, diamond tools and water jet cutting, nozzles requiring wear and abrasion resistance to siphoning, sanding and water jet cutting machines, etc. The wide range of applications that this material provides deserve to be taken into account in new research and product design projects.

The aim of this work is to be examined the sintering temperature used for boron carbide. The control of the temperature is implemented by using an infrared thermal camera.

\section{State of the art}

\footnotetext{
Corresponding author: nikistoimenow@gmail.com
}

The most famous $\mathrm{B}_{4} \mathrm{C}$ cold-sintering additive is carbon. Carbon additives are generally carried out by in-situ pyrolysis of a phenolic resin which serves as a compression agent and delivers $\sim 30 \%$ by weight of carbon upon decomposition. Schwetz and Vogt [4] first use a carbon additive in the form of a phenolic resin of very fine, pure, stoichiometric $\mathrm{B}_{4} \mathrm{C}$ with $10-22 \mathrm{~m}^{2} / \mathrm{g}$ of surface area. They note that the addition of carbon facilitating up to $98 \%$ of the theoretical density at 2150 ${ }^{\circ} \mathrm{C}$. At the same time, other independent studies have also demonstrated the importance of the carbon supplement $[5,6]$. Suzuki [5] synthesizes $B_{4} C$ with $25-30 \%$ by weight carbon supplements to $90-93 \%$ theoretical density at $2250{ }^{\circ} \mathrm{C}$ and monitors the formation of a liquid from the eutectic composition $(30 \%$ C). Later Schwetz and Grellner [7] examined in detail the effect of carbon addition. They found that only the use of a $\mathrm{B}_{4} \mathrm{C}$ highthroughput powder with a high surface area (over 15 $\mathrm{m}^{2} / \mathrm{g}$ ) and the addition of carbon could result in densified (over $95 \%$ of the theoretical density) finely-granulated microstructure articles.

\section{Used devices for achieving the study}

The high-temperature melting point of boron carbide requires Tammann furnace (fig. 1). The maximum temperature work of the furnace is $2200-2300{ }^{\circ} \mathrm{C}$, and the minimum is $1400{ }^{\circ} \mathrm{C}$. The samples are placed in graphite tubes with a clearance of 125-130 mm and a thickness up to $10 \mathrm{~mm}$. Their length is $1400 \mathrm{~mm}$. The reflecting graphite tube is with a diameter of the lumen up to 140 $\mathrm{mm}$ and a length of $1500 \mathrm{~mm}$. The isolation consists of a graphite powder. The power supply of the hightemperature Tammann furnace is based on IGBT technology. Also, a water-cooling system with high protections against incoming and outgoing low voltage, strong output current, and voltage, overheating. For 
achieving maximum performance of the furnace is mounted devices for automatic feeding and a device for receiving the finished products. Tammann furnace works in a controlled environment with protective gas, most commonly dissociated into hydrogen and nitrogen ammonia. The used technology can increase significantly the durability of the materials $[8,9,10]$.

This working principle of the Tammann furnace requires the usage of service (measuring) infrared window. For using infrared thermography, the service window must be from a material, transmitting in the infrared wavelength. Such materials are germanium, zinc selenide, amtir, quarts, etc. For this study is used a zinc selenide window.

The use of infrared window from zinc selenide glass preforms more accurate temperature measurement and control. The use of zinc selenide ( $\mathrm{ZnSe}$ ) glass in the Tammann furnace allows more accurate measurement of temperatures due to the linear characteristic of zinc selenide at temperatures above $700{ }^{\circ} \mathrm{C}$, another important advantage is that also be a gas filter will be used at high temperatures of $2000 \div 2300{ }^{\circ} \mathrm{C}$. Most often the transmittance of the window depends upon its thickness, used material, density, etc.

Today there is a wide market choice and different companies, which provides different thickness, material, etc. of infrared windows. This requires investigation and validation of the transmittance of the chosen infrared window. For that purpose is used an electrical furnace with a thermal couple working up to $1100{ }^{\circ} \mathrm{C}$, shown on fig. 2.

The high-temperature control is observed and measured with infrared thermal camera FLIR P640 (Fig. 3 ) with a field of view $24^{\circ} / 16^{\circ}$, a minimum range of measurement temperature with two regimes from $-40{ }^{\circ} \mathrm{C}$ to $120{ }^{\circ} \mathrm{C}$, from $0{ }^{\circ} \mathrm{C}$ to $+500{ }^{\circ} \mathrm{C}$, and for this study was performed calibration and software update for achieving measuring temperatures up to $2100{ }^{\circ} \mathrm{C}$. The camera temperature sensitivity is $0.06{ }^{\circ} \mathrm{C}$ at $30{ }^{\circ} \mathrm{C}$, detector matrix 640/480 pixels, integrated color digital camera, image settings, metering mode, various lenses, and management software $[9,11,12,13]$. The temperatures are validated with the build-in thermal couple of the electrical furnace.

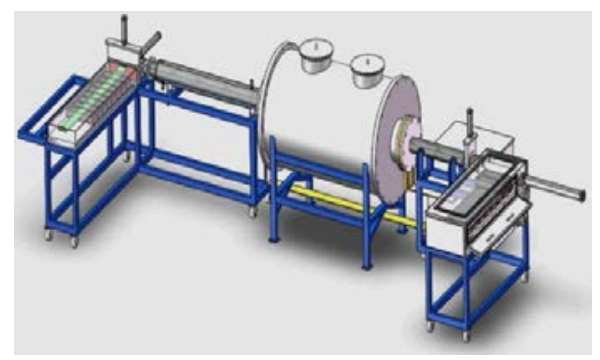

Fig. 1. Tamann furnace.

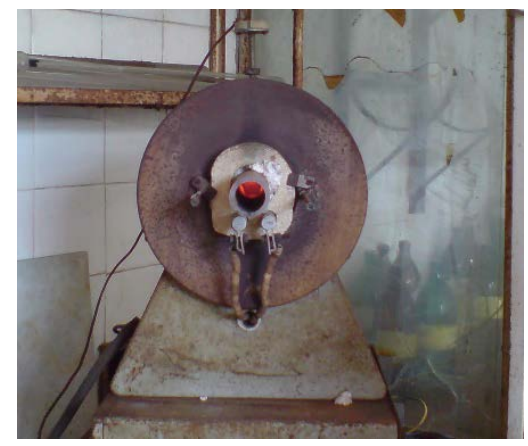

Fig. 2. Electric furnace.

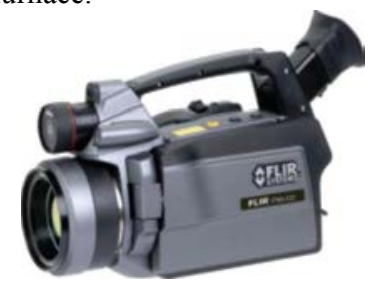

Fig. 3. Thermal camera.

\section{Experimental results}

The experiment is established in a laboratory with a controlled environment.

First is achieved the investigation for verifying the temperatures of the infrared thermal camera and the thermal couple from the electric furnace. The results from the thermal image, shown on fig. 4 matches to the furnace thermal couple. The emissivity coefficient is set to $\varepsilon=$ 0,98 , and the measured temperature in the $\mathrm{Bx} 1$ (Box 1) is $828^{\circ} \mathrm{C}$. Next step is to calibrate the zinc selenide glass, shown on fig. 5. It is clear that without setting the transmission coefficient, the temperature is $471,4{ }^{\circ} \mathrm{C}$. It is lower than the measured from the thermal couple of the furnace and from the thermal imaging camera.

Numerous experiments with different temperatures were made. Part of the measured temperatures are shown on fig. 6 is $915,6^{\circ} \mathrm{C}$. The measured temperature on fig. 7 is $1084^{\circ} \mathrm{C}$. For all measurements is chosen coefficient of transmissions, set to 0,41 and the temperatures are validated from the built-in thermal couple of the furnace.

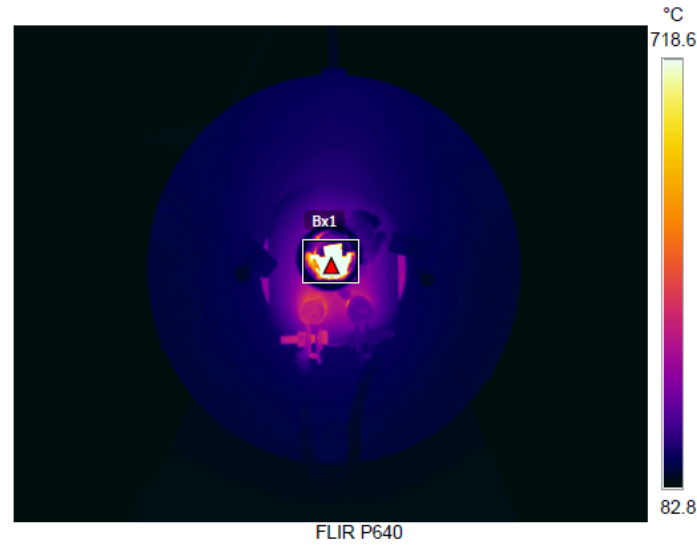

Fig. 4. Infrared image of examined detail. 


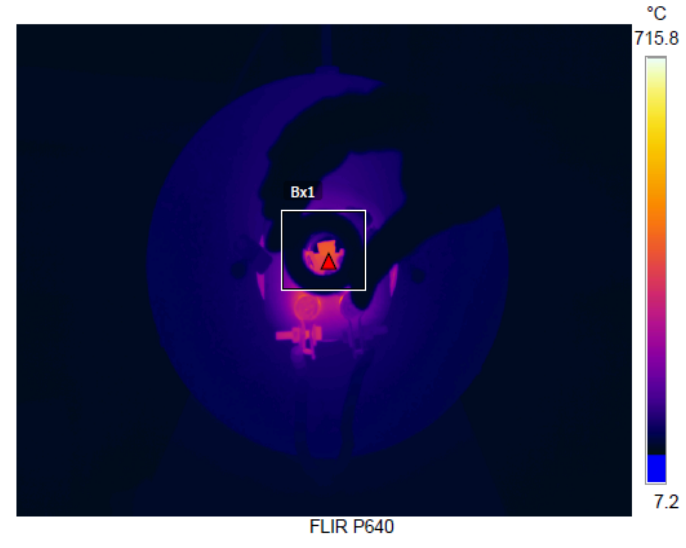

Fig. 5. Infrared image of examined detail with ZnSe glass.

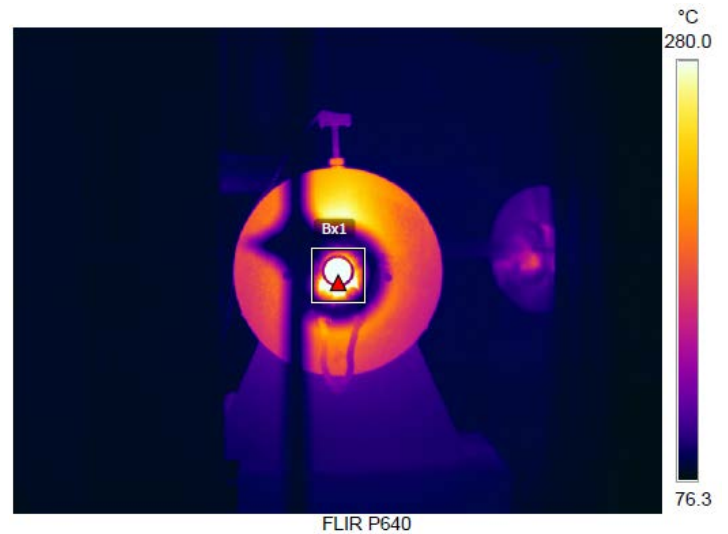

a) Infrared image

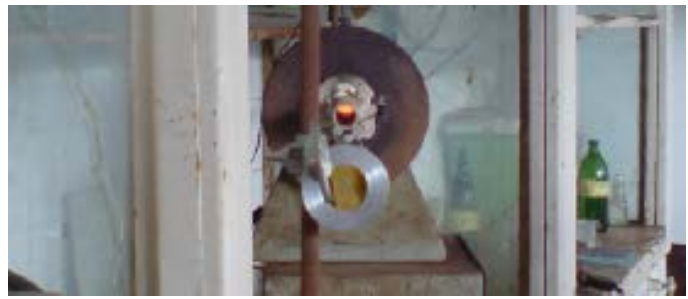

b) Digital image

Fig. 6. Testing with infrared $\mathrm{ZnSe}$ glass: a - infrared image of examined detail with $\mathrm{ZnSe}$ glass at $915^{\circ} \mathrm{C}$; b - digital image.

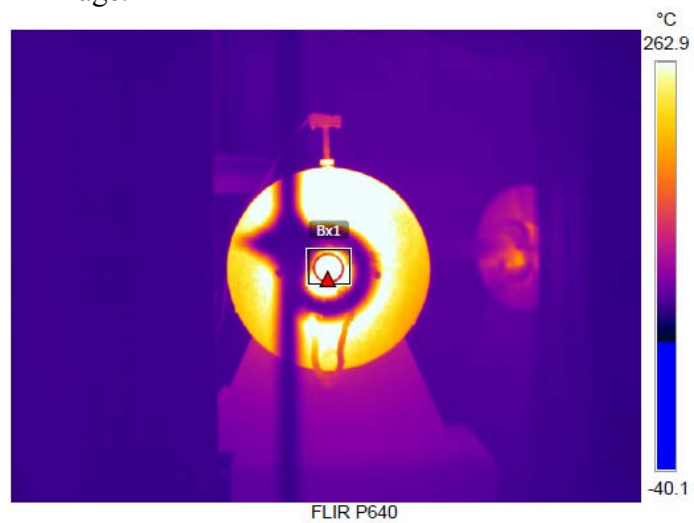

Fig. 7. Infrared image of examined detail with $\mathrm{ZnSe}$ glass at $1084{ }^{\circ} \mathrm{C}$.
After defining the transmission coefficient next step is to make an attempts to sinter boron carbide at various temperatures $1950 \div 2000{ }^{\circ} \mathrm{C}, 2050 \div 2100{ }^{\circ} \mathrm{C}$.

Industrial used powders of boron carbide in micro area are shown on table 1 . It is possible also the use of nano powders.

Table 1. Boron carbide particles size

\begin{tabular}{|l|l|}
\hline Surface area & \multicolumn{1}{|c|}{$18.8 \mathrm{~m}^{2} / \mathrm{g}$} \\
\hline Particle size & $90 \%$ of particles $\leq 2.99 \mu \mathrm{m}$ \\
& $50 \%$ of particles $\leq 0.84 \mu \mathrm{m}$ \\
& $10 \%$ of particles $\leq 0.24 \mu \mathrm{m}$ \\
\hline
\end{tabular}

The temperature is observed again with infrared camera trough service window using $3 \mathrm{~mm} \mathrm{ZnSe}$ glass. When the temperature rises above $2,100{ }^{\circ} \mathrm{C}$, boron carbide products will melt, and at temperatures lower than $1950{ }^{\circ} \mathrm{C}$ there will be no sintering. The sintering temperatures for boron carbide are determined by the activating additives. The measured temperatures are shown on fig 8 , with a detected temperature of 1650,4 ${ }^{\circ} \mathrm{C}$.

The controlled temperature prevented the boron carbide from melting and the sintered details, shown on fig. 11 .

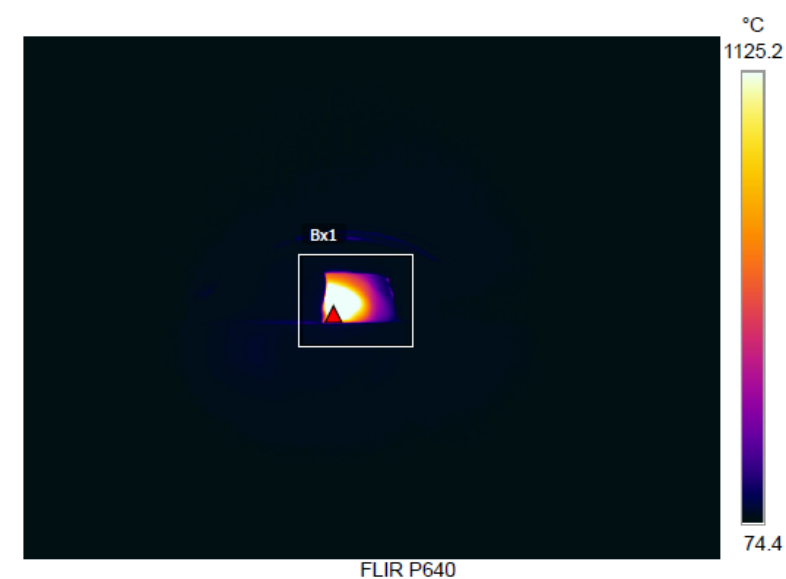

Fig. 8. Infrared image of examined detail with $\mathrm{ZnSe}$ glass at $1650,4^{\circ} \mathrm{C}$.

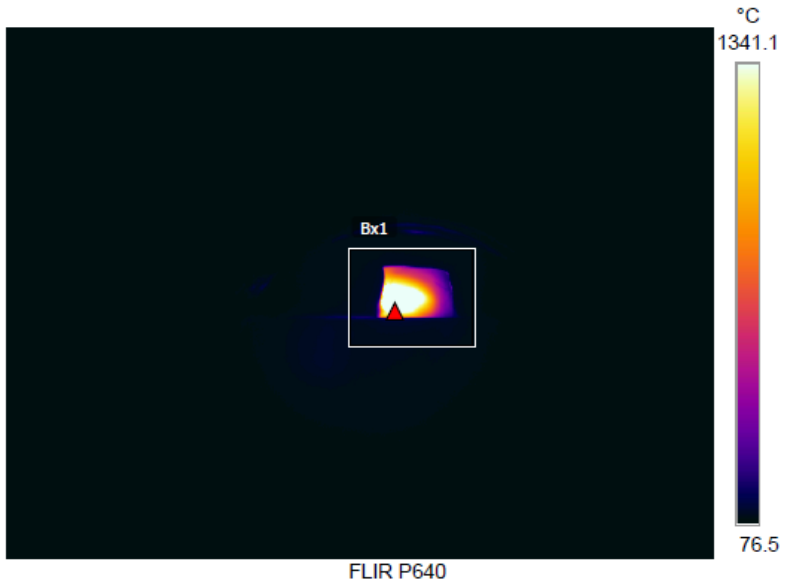

Fig. 9. Infrared image of examined detail with $\mathrm{ZnSe}$ glass at $1749,5{ }^{\circ} \mathrm{C}$. 


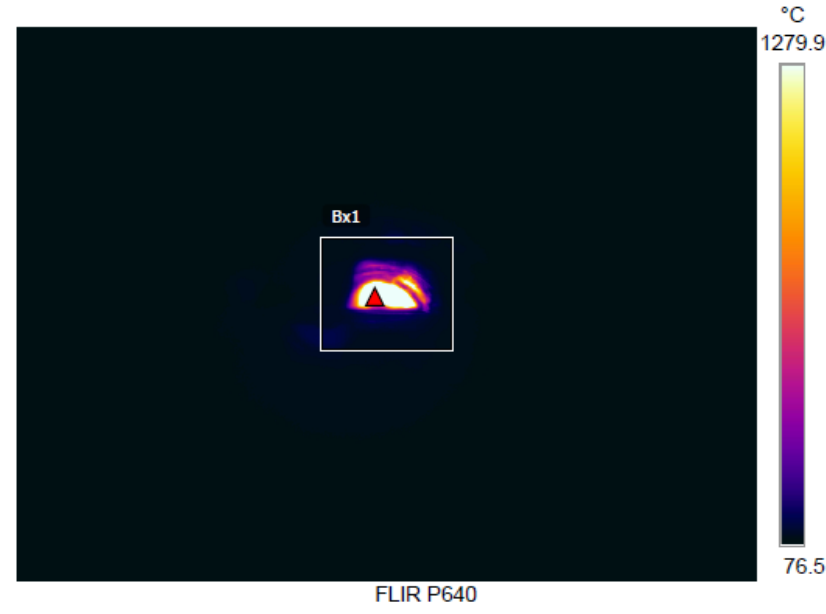

Fig. 10. Infrared image of examined detail with $\mathrm{ZnSe}$ glass at $2100{ }^{\circ} \mathrm{C}$.

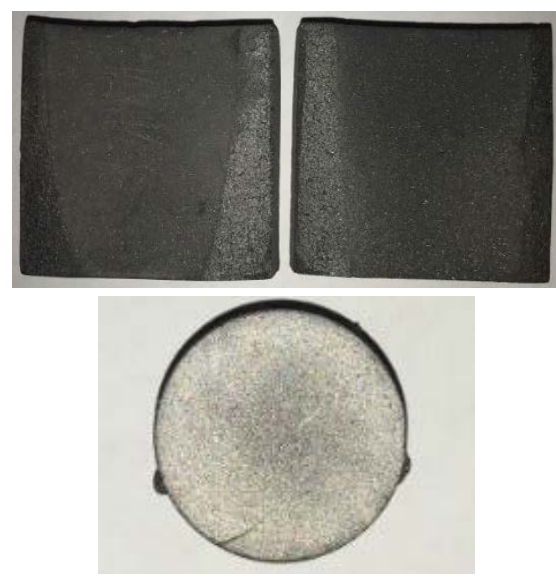

Fig. 11. Sintered Boron carbide details.

\section{Conclusion and future developments}

Calibrating the ZnSe glass with an electric furnace and its built-in thermal couple gives the possibilities to adequate and precise determination of the used $\mathrm{ZnSe}$ window transmission coefficient.

The strict control of the temperature during sintering the boron carbide gives the desired effect without melting the object.

High-temperature technology for the production of high strength and wear-resistant materials and alloys is based on the usage of nanoelements. Example of highwear resistant need is the mining industry and mills as well as the mill grinding bodies and media. It is an innovation for supplying Bulgarian companies with materials without the need for import of expensive materials, equipment, and technology. Those materials can be included in the crystal lattice of the resulting alloys, as well as catalysts for the synthesis and sintering processes.

Next step is to be examined the 3D internal structure of the boron carbide for cracks and other defects with 3D scanning computed tomography Nikon XT-H 225

Acknowledgments: The paper is partially supported by Bulgarian NFS Grant "Young Scientists - 2017" No DM 17/8 - 2017, and partially supported by the
Bulgarian Ministry of Education and Science under the National Research Programme "Young scientists and postdoctoral students" approved by DCM \# 577 / 17.08.2018.

\section{References}

1. R. R. Rigdway, "Boron Carbide. A New Crystalline Abrasive and Wear-Ressisting Product", Trans. Am. g: nanosolid feed Electrochem. Soc., 66, pp. 117-33, (1934).

2. F. Thevenot, Boron Carbide-A Comprehensive Review," J. Euro. Ceram. Soc., 6, pp. 205-225 (1990).

3. Cho N., Processing of Boron Carbide, Dissertation, Institute of Technology, (2006)

4. K. Schwetz and G. Vogt, "Process for the Production of Dense Sintered Articles of Boron Carbide," U.S. Patent 4,195,066 (1980).

5. H. Suzuki, T. Hasse, and T. Maruhama, "Effect of Carbon on Sintering of Boron Carbide", Yogyo Kyokai Shi, 87 340-33 (1978).

6. J. W. Henney and W. Grellner, "The Influence of Carbon on the Microstructure and Mechanical Properties of Sintered Boron Carbide," Brit. Patent. 2,014,193, (1978).

7. K. A. Schwetz, W. Grellner, and A. Lipp, "Mechanical Properties of HIP-Treated Sintered Boron Carbide," Inst. Phys. Conf. Ser. No. 75, Chapter 5, Adam Hilger Ltd., Bristol, 413-26, (1986)

8. Tamman Furnace - RUHSTRAT GMBH, Manual and Application, Berlin, (2012)

9. D. Karastoyanov, D. Ivanova, N. Stoimenov, Technology for production of high-temperature materials and alloys including nano elements, Recent Advances in Systems,19th International Conference on Systems (part of CSCC'15), Zakynthos Island, Greece, July 16-20, 2015, pp. 177-181, ISSN: 1790-5117, ISBN: 978-1-61804321-4. (2015)

10. D. D. Radev "Pressureless Sintering of Boron Carbide-Based Superhard Materials", Solid State Phenomena, Vol. 159, pp. 145-148, (2010)

11. M. Kandeva, B. Ivanova, D. Karastoyanov., Composite Coatings to Improve Durability of the Working Body of the Drill., 5th WORLD TRIBOLOGY CONGRESS WTC 2013, September 8-13, Torino, Italy (2013),

12. V. Ivanov, N. Stoimenov, D. Karastoyanov, T. Neshkov, L. Klochkov, Experimental study offurnace temperature for metallization of polypropylene, Part I. Production temperature analysis of a furnace for metallization of polypropylene and establishment of methodology for experimental study., Problems of Engineering Cybernetics and Robotics, vol. 67, „Prof. Marin Drinov" Publishing House of Bulgarian Academy of Sciences, Sofia, ISSN 0204-9848, pp 19-26 (2016) 
13. N. Stoimenov, L. Dimitrov, D. Karastoyanov, V. Georgieva, L. Klochkov, Experimental study of furnace temperature for metallization of polypropylene, Part II. Temperature differences analysis in heating unit for silver metallization of polypropylene., Problems of Engineering Cybernetics and Robotics, vol. 67, „Prof. Marin Drinov" Publishing House of Bulgarian Academy of Sciences, Sofia, ISSN 0204-9848, pp 27-33 (2016)
14. N. Stoimenov, L. Dimitrov, D. Karastoyanov, V. Georgieva, L. Klochkov, Experimental study of furnace temperature for metallization of polypropylene, Part III. Temperature differences analysis in heating unit set for zinc., Problems of Engineering Cybernetics and Robotics, vol. 67, „Prof. Marin Drinov“ Publishing House of Bulgarian Academy of Sciences, Sofia, ISSN 02049848, $\quad$ pp 34-42

(2016) 